\title{
Repair of type III common arterial trunk with modified Barbero-Marcial technique
}

\author{
Juan M. Aguilar, MD, ${ }^{a}$ Enrique Garcia, MD, PhD, ${ }^{a}$ Francesco G. Arlati, MD, ${ }^{b}$ and \\ Juan V. Comas, $\mathrm{MD}, \mathrm{PhD},{ }^{\mathrm{a}}$ Madrid Spain, and Milan, Italy
}

\footnotetext{
From the ${ }^{\mathrm{a} P e d i a t r i c ~ H e a r t ~ I n s t i t u t e, ~ U n i v e r s i t y ~ H o s p i t a l ~ T w e l f t h ~ o f ~ O c t o b e r, ~ M a d r i d, ~ S p a i n ; ~ a n d ~}{ }^{\mathrm{b}}$ Cardiologic Center Monzino, Milan, Italy.

Disclosures: Authors have nothing to disclose with regard to commercial support.

Received for publication April 9, 2015; revisions received July 7, 2015; accepted for publication July 12, 2015; available ahead of pring Aug 5, 2015.

Address for reprints: Francesco G. Arlati, MD, Via Carlo Parea 4, 20138 Milan, Italy (E-mail: francesco.arlati@ gmail.com).

J Thorac Cardiovasc Surg 2015;150:e69-70

$0022-5223 / \$ 36.00$

Copyright (c) 2015 by The American Association for Thoracic Surgery

http://dx.doi.org/10.1016/j.jtcvs.2015.07.033
}

Right ventricular outflow tract (RVOT) reconstruction is a controversial issue in common arterial trunk repair. Usually, this procedure is accomplished by interposition of a conduit, valve or nonvalved, between the right ventricle and the pulmonary arteries. Conduit degeneration is fast in patients aged $<12$ months, especially in those implanted in heterotopic position during the neonatal period, as in truncus arteriosus repair. ${ }^{1}$

In 1990, Barbero-Marcial and colleagues ${ }^{2}$ described a technique for RVOT reconstruction in Collet-Edwards ${ }^{3}$ type II common arterial trunk without the interposition of a conduit. This technique involves a direct anastomosis between the pulmonary trunk and the infundibular ventriculotomy.

In this article, we describe a modification of the BarberoMarcial technique to treat type III truncus arteriosus, which comprises the interposition of the left atrial appendage between the right ventricle and the pulmonary trunk. We present intraoperative pictures of a patient with a prenatal

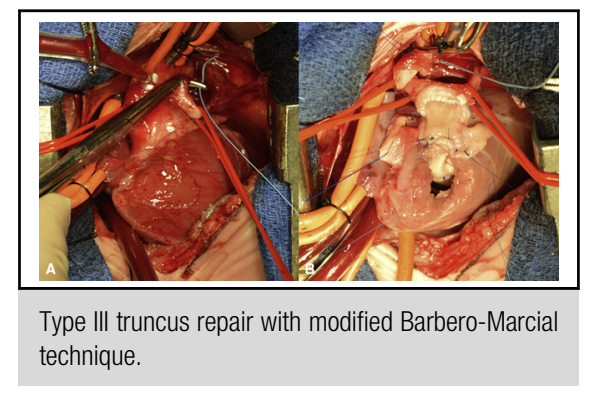

\section{Central Message \\ This paper reports an unconventional applica- tion of the modified Barbero-Marcial technique for type III truncus repair.}

See Editorial Commentary page e70.

diagnosis of type III common arterial trunk who underwent complete repair with a modified Barbero-Marcial technique at 3 weeks of age (Figures 1 and 2).

Early postoperative recovery was complicated by left ventricle dysfunction that required ECMO, probably because of inadequate myocardial protection caused by left main trunk distortion after pulmonary artery clamping. On postoperative day 6, the patient was weaned from ECMO support. Subsequently, he developed mainly diastolic right ventricle

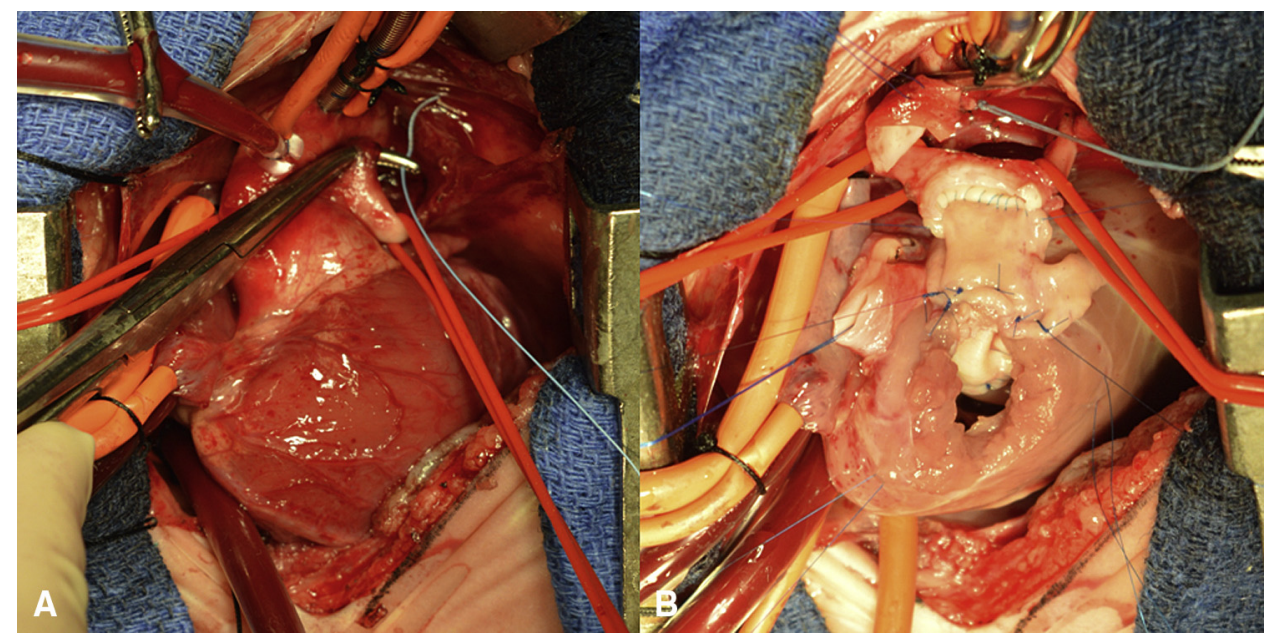

FIGURE 1. A, Collet-Edwards type III common arterial trunk showing ligation of a small arterial duct and left pulmonary artery isolation (red vessel loop). $\mathrm{B}$, Closure of the ventricular septal defect with a heterologous pericardial patch, and reconstruction of the posterior surface of the new right ventricular outflow tract with an anastomosis between the left atrial appendage and the posterior rim of the ventriculotomy proximally, and the posterior rim of the pulmonary trunk distally. 


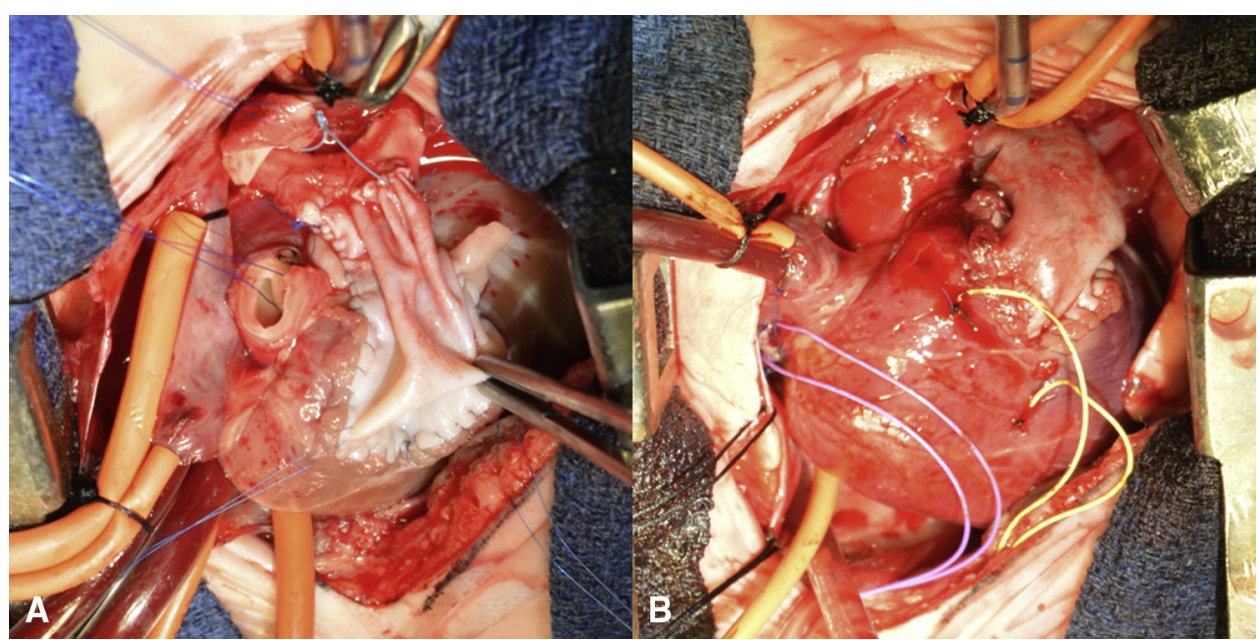

FIGURE 2. A, complete reconstruction of the right ventricular outflow tract with a heterologous pericardial patch. B, Final state after complete reconstruction.

dysfunction. After complete recovery with medical therapy he was discharged in good general condition.

\section{References}

1. Vitanova K, Cleuziou J, Hörer J, Kasnar-Samprec J, Vogt M, Schreiber C, et al. Which type of conduit to choose for right ventricular outflow tract reconstruction in patients below 1 year of age? Eur J Cardiothorac Surg. 2014;46:961-6; discussion 966.

2. Barbero-Marcial M, Riso A, Atik E, Jatene A. A technique for correction of truncus arteriosus types I and II without extracardiac conduits. J Thorac Cardiovasc Surg. 1990;99:364-9.

3. Collett RW, Edwards JE. Persistent truncus arteriosus; a classification according to anatomic types. Surg Clin N Am. 1949;29:1245-70.

\title{
EDITORIAL COMMENTARY
}

\section{Reconstruction without extracardiac conduit revisited}

\author{
Osami Honjo, MD, PhD
}

\footnotetext{
From the Division of Cardiovascular Surgery, Labatt Family Heart Centre, Toronto, Ontario, Canada; and the Division of Cardiovascular Surgery, Department of Surgery, The Hospital for Sick Children, University of Toronto, Toronto, Ontario, Canada.

Disclosures: Author has nothing to disclose with regard to commercial support.

Received for publication Aug 18, 2015; accepted for publication Aug 18, 2015; available ahead of print Sept 19, 2015.

Address for reprints: Osami Honjo, MD, PhD, Division of Cardiovascular Surgery, Department of Surgery, University of Toronto, 555 University Ave, Toronto, Ontario M5G1X8, Canada (E-mail: osami.honjo@ sickkids.ca).

J Thorac Cardiovasc Surg 2015;150:e70-1

$0022-5223 / \$ 36.00$

Copyright $($ c 2015 by The American Association for Thoracic Surgery

http://dx.doi.org/10.1016/j.jtcvs.2015.08.054
}

Patients with common arterial trunk (CAT) who have undergone neonatal biventricular repair are inevitably burdened with multiple catheter and surgical reinterventions on their right ventricle-to-pulmonary artery (PA) conduit and branch PAs. ${ }^{1}$ The lack of growth potential in a small right ventricle-PA conduit implanted in the neonatal period mandates early exchange surgery, and

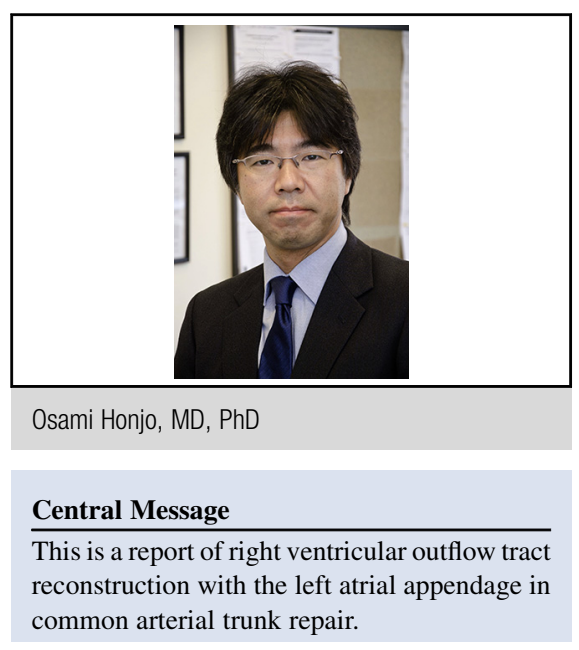

See Article page e69. 